\title{
IMPLEMENTASI WAVECOM DALAM MONITORING BEBAN LISTRIK BERBASIS MIKROKONTROLER
}

\author{
Husnibes Muchtar ${ }^{1}$, Asep Hidayat ${ }^{2}$ \\ ${ }^{1,2}$ Teknik Elektro, Fakultas Teknik Universitas Muhammadiyah Jakarta \\ Jl. Cempaka Putih Tengah 27 Jakarta 10510 \\ *Email : ibessaja@yahoo.com
}

\begin{abstract}
ABSTRAK
Pembuatan Implementasi wavecom dalam monitoring beban listrik berbasis mikrokontroler dimaksudkan untuk mempermudah konsumen yang masih menggunakan KWH Meter Analog. Alat ini dilengkapi Sensor arus, sensor tegangan, arduino nano, mikrokontroler AT328, menggunakan juga sebuah modul wavecom $1306 B$ sebagai penghubung yang dapat meneruskan data ke Ponsel. Ketika pengguna listrik ingin melihat beban dan biaya tagihan listrik setiap waktu, pengguna hanya mengirim sms sesuai format yang telah disimpan dalam program arduino. Modul wavecom memberi balasan sesuai perintah pengguna yang di perintah oleh mikrokontroler.
\end{abstract}

Kata kunci: Sensor arus, Sensor tegangan, Arduino nano.

\begin{abstract}
Making The implementation of wavecom in microcontroller based monitoring electrical load is intended to facilitate consumers who are still using Analog Meter KWH. The tool is equipped with current sensor, voltage sensor, arduino nano, micro AT328, using also a wavecom module $1306 B$ as a liaison to pass data to the phone. When the power users want to see the burden and cost of the electric bill every time, users simply texted according to the format that has been stored in arduino program. Module wavecom reward corresponding user commands in the command by the microcontroller.
\end{abstract}

Keywords: Sensor current, voltage sensors, Arduino nano.

\section{PENDAHULUAN}

Listrik merupakan salah satu unsur penunjang dalam kehidupan manusia, tanpa listrik sudah pasti manusia akan mengalami kesulitan dalam menjalani kesehariannya.

Baru baru ini kita telah dipusingkan dengan kenaikan TDL (Tarif Dasar Listrik) yang membuat kita sebagai pengguna jasa PLN lebih berfikir lagi bagaimana caranya untuk mengetahui seberapa banyak beban yang sedang kita gunakan pada suatu waktu tertentu dan total tarif pemakaian sampai saat itu. Hal ini yang melandasi penulis untuk merancang suatu alat yaitu Sistem Monitoring Pemakaian Beban Listrik Melalui SMS. Alat ini merupakan inovasi perpaduan antara hardware dan software yang dirancang sedemikian rupa sehingga dapat mempermudah konsumen untuk mengetahui jumlah biaya listrik setiap waktu dengan menggunakan sms. 


\section{Kajian Pustaka}

\section{a. Mikrokontroler Atmega 328}

Microcontroller adalah suatu terobosan dalam teknologi mikroprosessor dan mikrokomputer, perbedaannya mikrokontroler hanya digunakan untuk menangani suatu aplikasi tertentu. Perbedaan mikrocontroller lain terletak pada perbandingan RAM dan ROM. Komputer memiliki RAM dan ROM yang besar, tetapi pada mikrokontroler sangat terbatas. ROM pada mikrokontroler digunakan untuk menyimpan program, sedangkan RAM untuk menyimpan data sementara. Mikrokontroler terdiri dari ALU (Aritmatic Logical Unit), CU (Control Unit), PC (Program Counter), SP (Stack Pointer), Register, Timer, Interupt. Mikrocontroller juga dilengkapi dengan beberapa piranti pendukung lain seperti ROM (Read Only Memory), RAM (Random Accses Memory), decoder, communication interface, input/output (I/O) serial atau parallel.

\begin{tabular}{|c|c|c|c|}
\hline \multirow{2}{*}{ (PCINT14/RESET) PC6 } & \multicolumn{2}{|c|}{ ד } & \\
\hline & 1 & 28 & PC5 (ADC5/SCL/PCINT13) \\
\hline (PCINT16/RXD) PDO & 2 & 27 & P PC4 (ADC4/SDA/PCINT12) \\
\hline (PCINT17/TXD) PD1 I & 3 & 26 & P РC3 (ADC3/PCINT11) \\
\hline (PCINT18/INT0) PD2 & 4 & 25 & P PC2 (ADC2/PCINT10) \\
\hline (PCINT19/OC2B/INT1) PD3 & 5 & 24 & P PC1 (ADC1/PCINT9) \\
\hline (PCINT20/XCK/TO) PD4 & 6 & 23 & P PCO (ADCO/PCINT8) \\
\hline vCc E & 7 & 22 & GND \\
\hline GND & 8 & 21 & AREF \\
\hline (PCINT6/XTAL1/TOSC1) PB6 L & 9 & 20 & avcc \\
\hline (PCINT7/XTAL2/TOSC2) PB7 L & 10 & 19 & PPB5 (SCK/PCINT5) \\
\hline (PCINT21/OCOB/T1) PD5 & 11 & 18 & P PB4 (MISO/PCINT4) \\
\hline (PCINT22/OCOA/AINO) PD6 & 12 & 17 & F PB3 (MOSI/OC2A/PCINT3) \\
\hline (PCINT23/AIN1) PD7 & 13 & 16 & F PB2 (SS/OC1B/PCINT2) \\
\hline (PCINTO/CLKO/ICP1) PBO & 14 & 15 & GPB1 (OC1A/PCINT1) \\
\hline
\end{tabular}

Gambar 1. Pin Maping ATmega 328

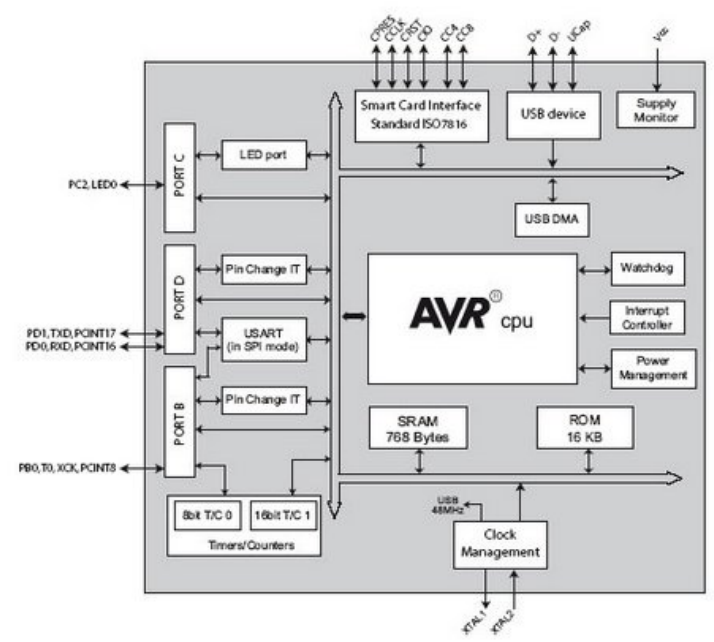

Gambar 2. Block Diagram Microcontroller ATmega328

\section{b. Arduino Nano}

Arduino Nano adalah sebuah board mikrokontroler yang didasarkan pada ATmega328. Arduino Nano mempunyai 14 pin digital input/output (6 di antaranya dapat digunakan sebagai keluaran PWM), 6 masukan analog, sebuah osilator Kristal $16 \mathrm{MHz}$, sebuah koneksi USB, sebuah power jack, sebuah ICSP header, dan sebuat tombol reset. Arduino Nano memuat semua yang dibutuhkan untuk menunjang mikrokontroler, mudah menghubungkannya ke sebuah komputer dengan sebuah kabel USB atau mensuplainya dengan sebuah adaptor AC ke DC atau menggunakan baterai untuk memulainya.

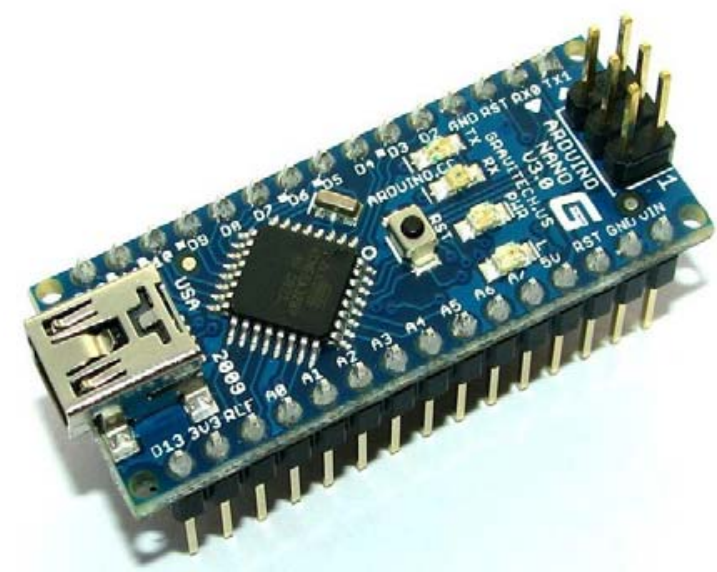

Gambar 3. Arduino Nano

\section{c. Modem GSM Wavecom}

Wavecom adalah pabrikan asal Perancis (bermarkas di kota Issy les Moulineaux, Perancis) yaitu Wavecom SA yang berdiri sejak 1993 bermula sebagai biro konsultan teknologi dan sistim jaringan nirkabel GSM, dan pada 1996 Wavecom mulai membuat desain daripada modul wireless GSM pertamanya dan diresmikan pada 1997, bentuk modul GSM pertama berbasis GSM dan pengkodean khusus yang disebut AT Command.

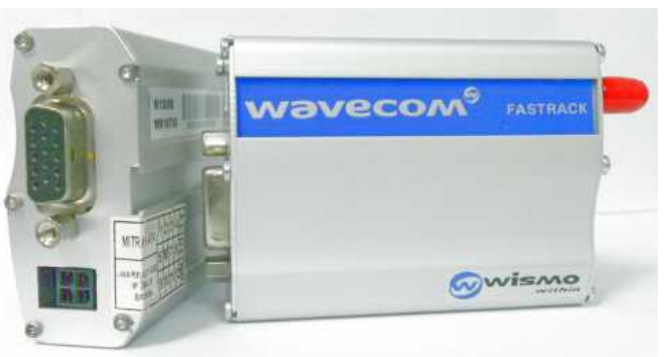

Gambar 4. Modem Wavecom 1306B 


\section{d. Sensor Arus}

Sensor arus adalah perangkat yang mendeteksi arus listrik (AC atau DC) di kawat, dan menghasilkan sinyal sebanding dengan itu. Sinyal yang dihasilkan bisa tegangan analog atau arus atau bahkan digital. Hal ini dapat kemudian digunakan untuk menampilkan arus yang akan diukur dalam ammeter atau dapat disimpan untuk analisis lebih lanjut dalam sistem akuisisi data atau dapat dimanfaatkan untuk tujuan monitoring.
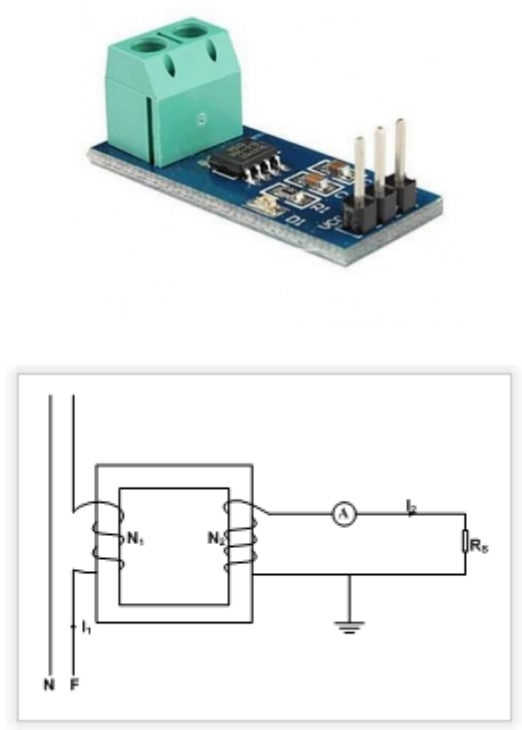

Gambar 5. Gambar Sensor Arus

\section{Perancangan Sistem}

Pada penelitian ini penulis merancang suatu alat sensor yang difungsikan sebagai monitoring keadaan beban listrik yang diaplikasikan untuk memberikan informasi kepada pengguna melalui Short Message Service. Dalam perancangan alat ini digunakan Arduino Nano sebagai controller, Modul Wavecom 1306B sebagai Interface SMS, Modul Arus ASC 712 sebagai alat ukur arus, Trafo stepdown berserta rangkaian penyearah gelombang penuh sebagai sensor tegangan dan Bohlam.

sebagai beban. Arsitektur umum dari alat yang penulis susun dapat dilihat pada Gambar 3.1.

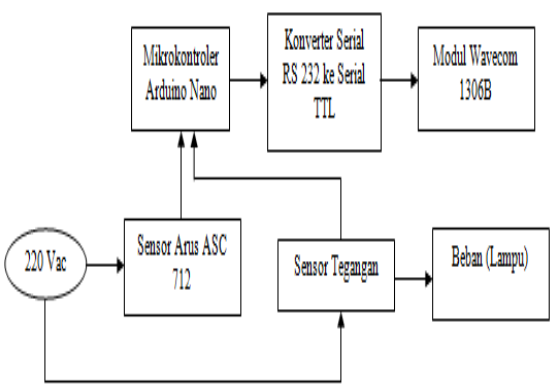

Gambar 6. Blog diagram sistem

\section{a. Perancangan Hardware}

Perangkat keras yang digunakan dalam sistem ini adalah perangkat keras yang mendukung proses penerimaan, pengiriman, pengolahan data dan perangkat keras lain yang mendukung, adapun perangkat keras yang digunakan dalam perancangan ini diantaranya sebagai berikut:

1. Mikrokontroler berbasis Arduino tipe NANO

2. Sensor Arus

3. Sensor Tegangan

4. Modul Wavecom 1306B

5. Modul Konverter Serial RS 232 ke Serial TTL

\section{b. Interface Antara Modul Wavecom dengan Arduino}

Interface yang di gunakan agar modul wavecom dan Arduino dapat berkomunikasi dengan menggunakan Serial dimana digunakan konverter Serial RS232 yang di miliki Modul Wavecom menjadi Serial TTL yang dimiliki oleh mikrokontroler Arduino. 


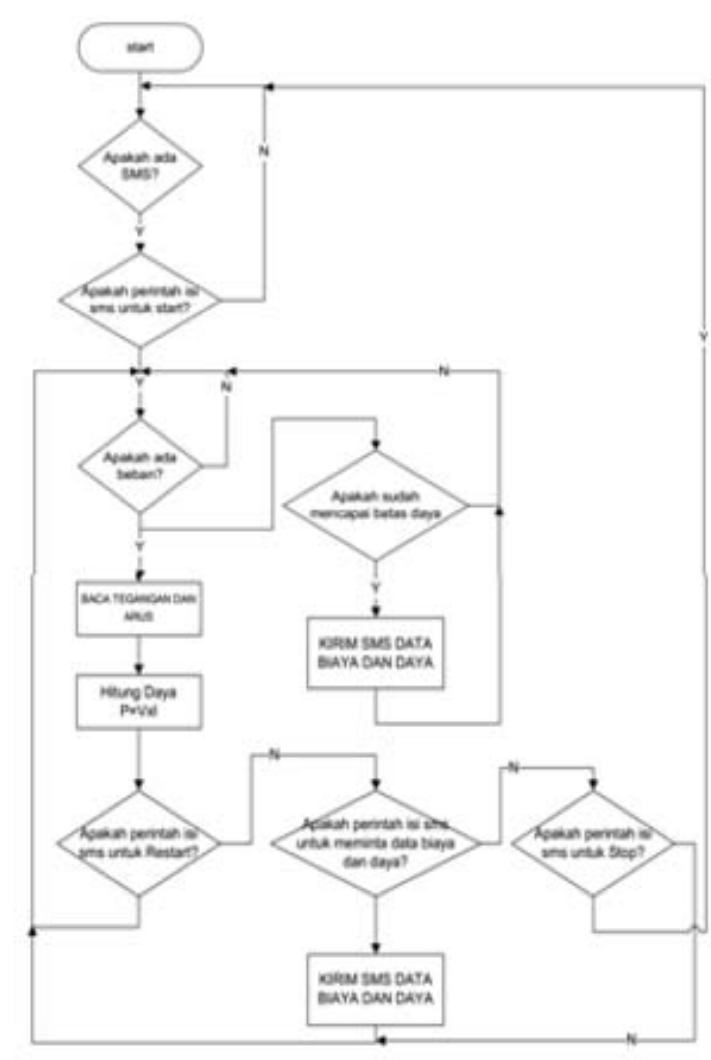

c. Interface Antara Modul Sensor Arus ASC 712 dengan Arduino

Modul Sensor Arus ASC 712 digunakan untuk mengukur besar arus yang di pakai dengan output tegangan yang linier dengan arus beban sesuai dengan gambar berikut.

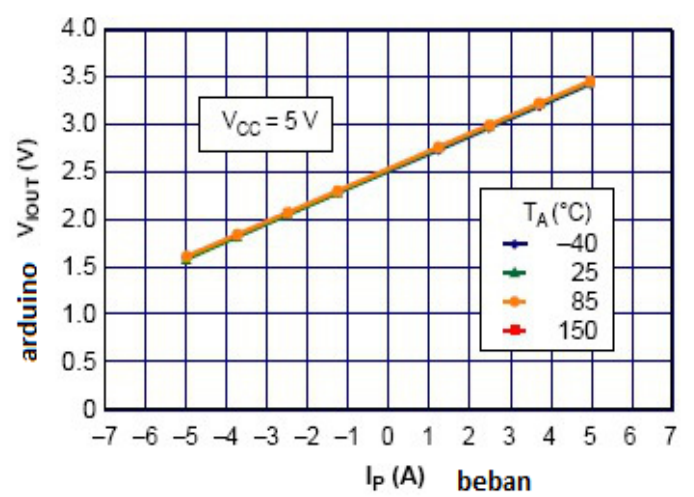

Gambar 7. Interface AntaraModul Sensor Arus ASC 712 denganArduino

\section{d. Interface Antara Sensor Tegangan dengan Arduino}

Terjadi hubungan antara trafo stepdown kemudian disearahkan oleh diode bridge (penyearah gelombang penuh) yang berfungsi untuk menurunkan tegangan dari $220 \mathrm{~V}$

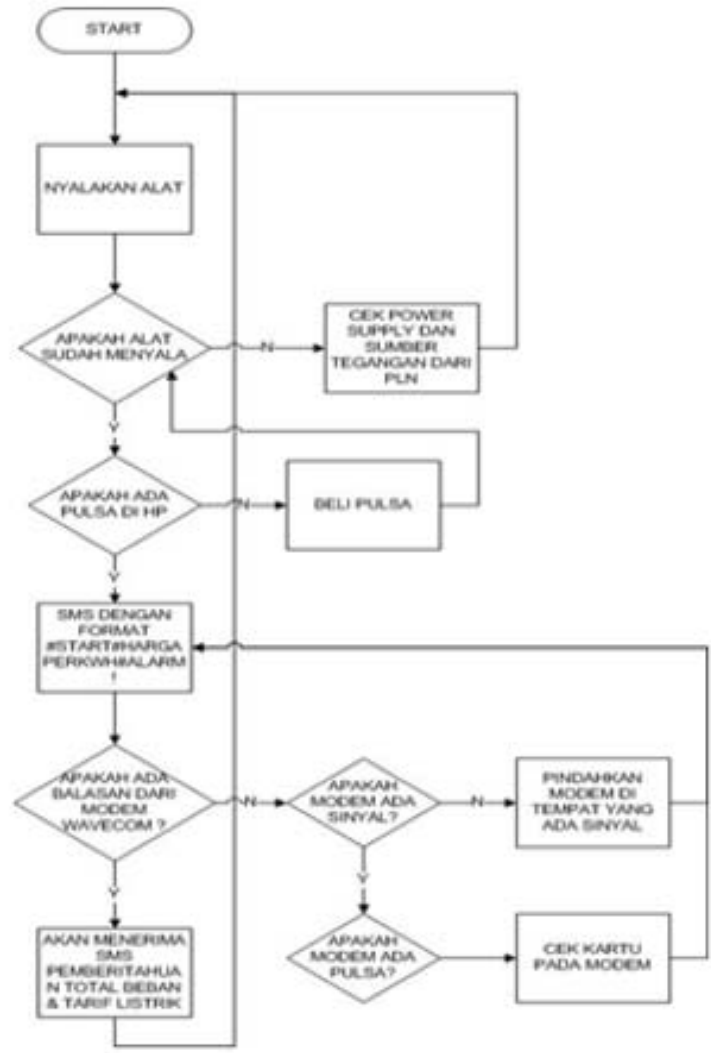

menjadi 3V yang kemudian disearahkan. Yang selanjutnya terkoneksi ke arduino nano.

\section{PENGUJIAN DAN ANALISA DATA a. Pengujian Wavecom}

Tujuan pengujian ini adalah untuk mengetahui respons kerja Wavecom terhadap input digital dari micro controller dengan output berupa pemberitahuan via sms.

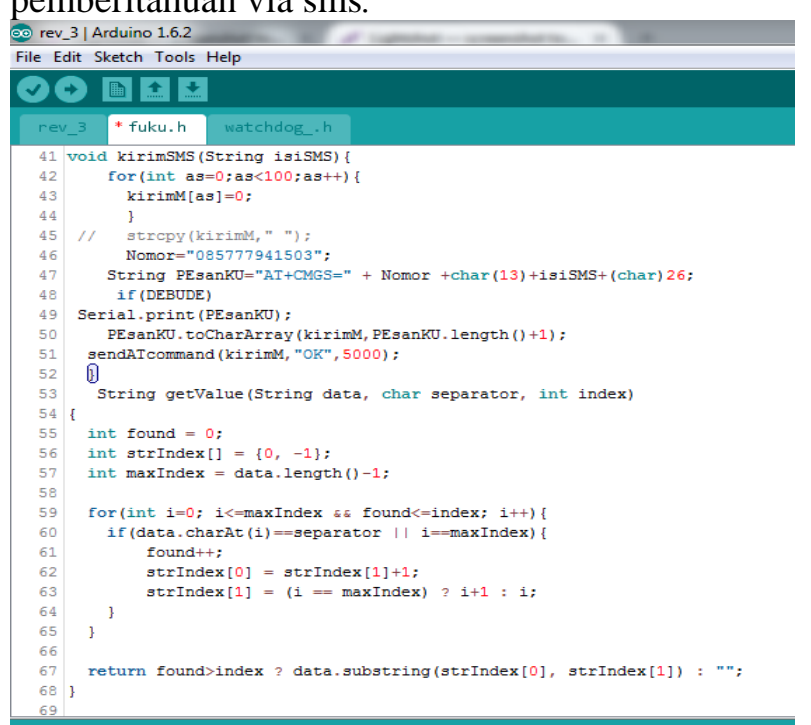

Gambar 8. Program pengujian 
Dari data di atas dapat disimpulkan bahwa modul wavecom dapat bekerja hanya dengan sistem sms dan dengan format sms yang telah ditentukan melalui Program Arduino.

\section{b. Pengujian Via SMS}

Pengujian berikut adalah penghitungan secara otomatis melalui program \& SMS. Sebagai simulasi untuk harga per Kwh adalah sebesar Rp. 1300,00.
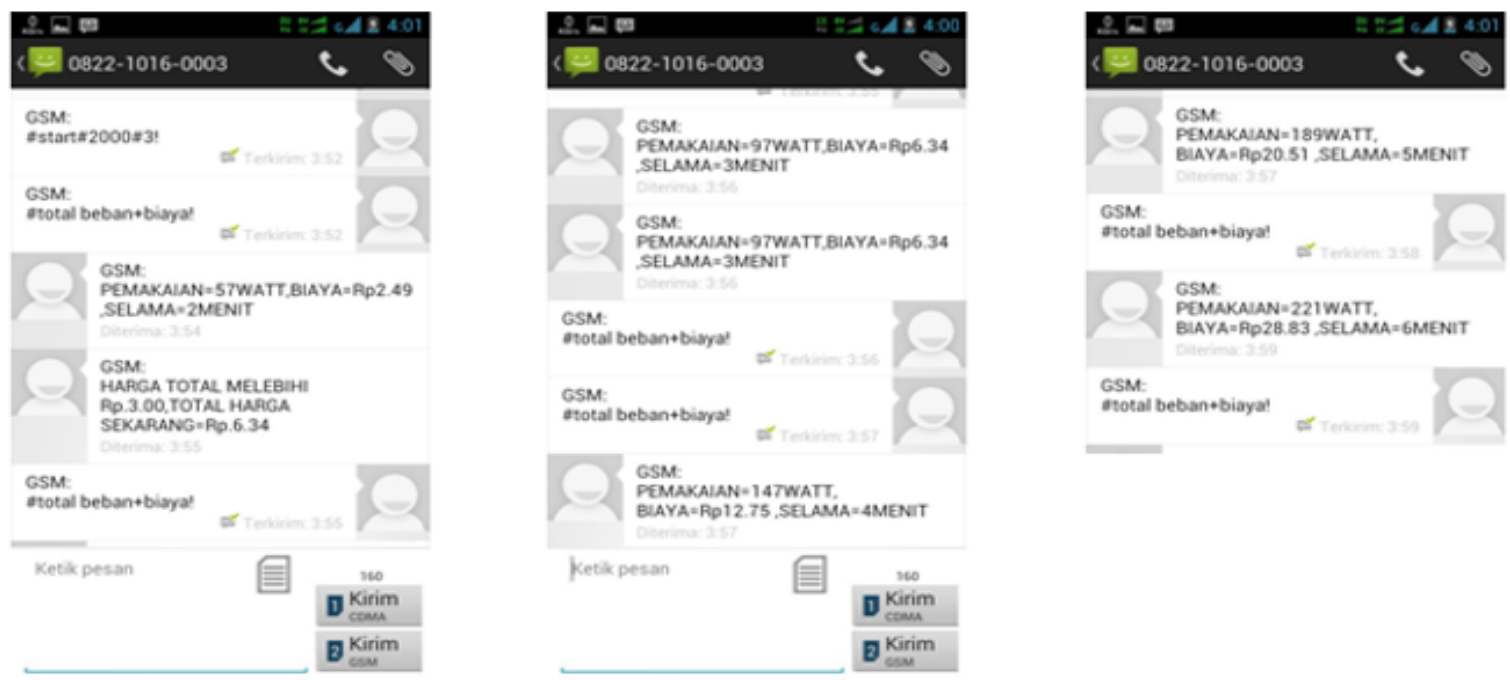

Tabel 1.Tabel pengujian selama 6 menit melalui SMS

\begin{tabular}{|c|c|c|c|}
\hline No & $\begin{array}{c}\text { Pengujian (dalam hitungan } \\
\text { menit) }\end{array}$ & $\begin{array}{c}\text { Pemakaian } \\
\text { Beban }\end{array}$ & Biaya \\
\hline 1 & 2 menit & $57 \mathrm{~W}$ & Rp. 2.49 \\
\hline 2 & 3 menit & $97 \mathrm{~W}$ & Rp. 6.34 \\
\hline 3 & 4 menit & $147 \mathrm{~W}$ & Rp. 12.75 \\
\hline 4 & 5 menit & $189 \mathrm{~W}$ & Rp. 20.51 \\
\hline 5 & 6 menit & $221 \mathrm{~W}$ & Rp. 28.83 \\
\hline
\end{tabular}

\section{PENUTUP}

Setelah membangun algoritma serta melakukan pengujian pada program dan System Monitoring arduino, ada beberapa hal yang dapat disimpulkan :

1) Algoritma yang digunakan pada sistem ini telah dirancang sesuai dengan apa yang telah di rumuskan, dimana perangkat dapat beroperasi sesuai dengan Perintah Arduino.

2) Sistem dapat bekerja hanya dengan 1 nomor handphone yang telah didaftarkan melalui Program Arduino yang kemudian akan ditampilkan lewat perantara SMS pada handphone tersebut.

3) Jumlah beban \& tarif listrik akan ditentukan berdasarkan dari pemakaian listrik, semakin banyak beban yang digunakan konsumen maka semakin besar tarif listrik yang akan tampil pada SMS.

\section{DAFTAR PUSTAKA}

Allegro. 2005. ACS712ELC-20A, Bidirectional $1.5 \mathrm{~m} \Omega$ Hall Effect Based Linear Current Sensor with Voltage Isolation and 20 A Dynamic Range, Worcester, Allegro Micosystems,In

Introduction to Arduino A piece of cake, Alan G. Smith, 2011

Basic Pulse Width Modulation Fall 2011 Gerald Recktenwald, 2012

Arduino-Based Dataloggers: Hardware and Software David R. Brooks Institute for Earth Science Research and Education V 1.2, June, 2015 